\title{
Study on the Electrochemical Corrosion and Scale Growth of Ductile Iron in Water Distribution System
}

\author{
Hao Guo ${ }^{1, *}$, Yimei Tian ${ }^{1}$, Hailiang Shen ${ }^{2}$, Xingfei Liu ${ }^{1}$, Ying Chen ${ }^{1}$ \\ ${ }^{1}$ School of Environmental Science and Engineering, Tianjin University, Tianjin 300072, China. \\ ${ }^{2}$ GHD, 651 Colby Drive, Waterloo, ON, Canada, N2V $1 \mathrm{C} 2$. \\ *E-mail: tjuguohao@163.com
}

doi: $10.20964 / 2016.08 .03$

Received: 8 April 2016 / Accepted: 22 May 2016 / Published: 7 July 2016

\begin{abstract}
A simulated water distribution system (WDS) combining specialized coupon test units and an electrochemical measurement cell is designed to provide an actual pipe corrosion environment. Coupon test is used to obtain the scale morphology and corrosion rate (CS), and provide scale samples for physicochemical characteristic analysis. Electrochemical impedance spectroscopy (EIS) is conducted simultaneously to display the scale structure change. Three corrosion stages are observed during a 32-day circulation. In initial stage (before day 4), the thin double-layer scales fast form inducing a sharp decline of CS $(0.9455 \sim 0.1492 \mathrm{~mm} / \mathrm{a})$. In developmental stage (day 4 16), the loose scales grow uniformly and the CS decreases slowly $(0.1492 \sim 0.0936 \mathrm{~mm} / \mathrm{a})$. In stable stage (after day 16), the protective scales with a compact outside layer finally form, and the CS maintains at a low value around $0.0900 \mathrm{~mm} / \mathrm{a}$. EIS fitting results showed that the stable scales consisted of a compact outside layer and a porous inside layer. In the stable stage, the increasing content of goethite and calcite slows the rate of dissolved oxygen diffusing through the scales, resulting in mass diffusion turning to be the rate-determining step of corrosion. Finally the mechanism of scale growth and localized tubercle formation is proposed.
\end{abstract}

Keywords: corrosion scales; EIS; XRD; ductile Iron; water distribution system

\section{$\underline{\text { FULLTEXT }}$}

(C) 2016 The Authors. Published by ESG (www.electrochemsci.org). This article is an open access article distributed under the terms and conditions of the Creative Commons Attribution license (http://creativecommons.org/licenses/by/4.0/). 